\title{
Indomethacin and the Cardiopulmonary Adaptations of Transition
}

\author{
CATHY HAMMERMAN AND EMILE M. SCARPELLI \\ Department of Pediatrics, University of Chicago, Chicago, Illinois 60637, and Albert Einstein College of \\ Medicine, Yeshivah University, Bronx, New York 10461
}

\begin{abstract}
Summary
The present investigation examines the biochemical and physiologic changes produced in fetal rabbit lungs by adding a prostaglandin synthetase inhibitor, sodium indomethacin trihydrate, to the pulmonary perfusate. A control group was similarly perfused without adding indomethacin. The ductus arteriosus was ligated and perfusion was then continued for $2 \mathrm{~h}$ while pulmonary artery pressures were monitored. At the end of this period, with perfusion continuing, the lungs were inflated with air at $5 \mathrm{~cm}$ $\mathrm{H}_{2} \mathrm{O}$ increments. Volume changes were recorded. After deflation, the lungs were lavaged with normal saline. Phospholipids were extracted from lung homogenates and lavage. Total lipid phosphorus was determined. Pulmonary vascular resistances in both groups manifested a sharp increase in pressure with ligation of the ductus. After $2 \mathrm{~h}$ of perfusion, pulmonary pressures in the control groups had returned very nearly to preligation levels, while in the indomethacin-treated group, pulmonary pressures remained significantly elevated. The first full inflation produced a slight fall in pulmonary vascular resistance in all control animals and a slight rise in all the treated rabbits. Perfused but untreated lungs had higher volumes during inflation as compared to both indomethacin-perfused lungs and unperfused untreated lungs. In this model, prostaglandins appear to have a significant role at two key points in transition: 1) the gradual accommodation to mechanically or hemodynamically mediated increases in pulmonary vascular resistance and 2) the drop in pulmonary vascular resistance which occurs with the first inflation of the lungs. No direct effect of prostaglandin inhibition on surfactant production was documented.
\end{abstract}

\section{Abbreviation}

PVR, pulmonary vascular resistance

Successful transition from intrauterine existence to extrauterine life requires major adaptations within the first few minutes of life. Most urgent among these changes is the shift from fluidfilled lungs of the fetus to the air-filled respiratory organs of the newborn, together with a dramatic redistribution of blood flow to allow adequate perfusion of these newly functioning lungs. This is accomplished through rapid dilatation of the pulmonary vascular bed. The role played by prostaglandin mediators in this process remains uncertain. This study was undertaken to examine what role, if any, prostaglandins play in the pulmonary and vascular components of the transitional period and the first breath.

Received July 6, 1983; accepted Feburary 7, 1984.

Correspondence should be addressed to Cathy Hammerman, M.D., University of Chicago. Department of Pediatrics, 5841 South Maryland Avenue, Box 325, Chicago. IL 60637.

This work was partially supported by National Heart, Lung, and Blood Institute Grants HL 07060 and HL 23995.
Prostaglandins are biologically active compounds with multisystemic effects. A large surge in prostaglandin production occurs in the perinatal period, both in animals (5) and in humans (6), probably a response to the role of prostaglandins in the induction of labor. This surge presents the neonate with an increased complement of circulating prostaglandins. These compounds have been shown to have modulating effects on pulmonary vascular resistance under certain circumstances (4) and have been postulated to alter surfactant release (7) under other circumstances.

The present investigation examines the biochemical and physiologic changes produced in fetal rabbit lungs by adding a prostaglandin synthetase inhibitor, sodium indomethacin trihydrate, to the pulmonary perfusate while artificially inflating the lungs.

\section{MATERIALS AND METHODS}

Pregnant New Zealand White rabbits at 27 days of gestation were anesthetized with sodium pentobarbital, $30 \mathrm{mg} / \mathrm{kg}$ IV. The uterus was incised and one fetus, randomly selected, was delivered. The neck was immediately compressed with a ligature to prevent air entry into the lungs. The uterus and skin were then closed with clamps and the mother was kept anesthetized for the duration of the experiment. Subsequent fetuses were thus able to be easily delivered through the same uterotomy.

The delivered fetus was then weighed and a polyvinyl cannula, filled with normal saline, was inserted into the trachea through a neck incision, and ligated in place. Care was taken not to allow any air entry into the trachea at this point. This could be verified by observation of movement of fetal pulmonary fluid from the lungs into the tracheal cannula.

Following removal of the anterior thorax, the ductus arteriosus was isolated by blunt dissection and surrounded by a 3-0 silk ligature, and the ends were tagged but not tied. An incision was then made in the right ventricle and a second saline-filled polyvinyl cannula was inserted and threaded up into the main pulmonary artery, proximal to the origin of the ductus arteriosus and ligated in place.

Both cannulas were connected to Statham P23DB pressure transducers. Fluids were infused via the pulmonary artery catheter at a rate of $1 \mathrm{cc} / \mathrm{min}$. using a polystaltic pump (Buchler Industries, Fort Lee, NJ). Control animals $(n=5)$ received buffered electrolyte solution equilibrated with $3 \% \mathrm{O}_{2}$; treated animals $(n=5)$ received buffered electrolyte solution with $3 \%$ $\mathrm{O}_{2}$ and $50 \mu \mathrm{g} / \mathrm{ml}$ sodium indomethacin trihydrate.

Five minutes after pulmonary artery pressures stabilized, the ductus arteriosus was ligated and perfusion was then continued for $2 \mathrm{~h}$ while pulmonary artery pressures were monitored. At the end of this period, with perfusion continuing, the lungs were then inflated with air at $5 \mathrm{~cm} \mathrm{H}_{2} \mathrm{O}$ increments by raising the water level in a cylinder attached to the tracheal cannula. Volume changes were recorded 2 min after each pressure adjustment from the meniscus of the attached pipette. The maximum pres- 
sure applied was 35 or $40 \mathrm{~cm} \mathrm{H}_{2} \mathrm{O}$, a limit established for each set of lungs by the point at which the lungs appeared grossly to be uniformly inflated. Pressure was then decreased by $5 \mathrm{~cm} \mathrm{H}_{2} \mathrm{O}$ decrements via a drainage stopcock, again recording volumes as before. Development of air leaks disqualified the entire preparation.

After deflation, the lungs were lavaged through the tracheal cannula with normal saline 4 times $/ \mathrm{min} \times 10 \mathrm{~min}$. This lavage fluid was frozen for subsequent phospholipid analysis. Perfusion was then discontinued; the lungs were excised, homogenized, and frozen for phospholipid analysis. Lavage fluid within a group had to be pooled for analysis since the yield of phospholipids was so small.

Phospholipid. Phospholipids were extracted from lung homogenates and lavage by the Folch (8) method using chloroform/ methanol, 2:1. The lipid phase was washed with chloroform/ methanol/water (3:48:47). Total lipid phosphorus was determined according to a modification of the technique of Beveridge and Johnson (2). The sample was digested with $10 \mathrm{M}$ sulfuric acid, the excess organic matter was oxidized with concentrated $\mathrm{HNO}_{3}$, and color was developed with molybdate and hydrazine measured spectrophotometrically at $750 \mathrm{~nm}$.

Phospholipids were separated by two-dimensional thin layer chromatography on plates precoated with silica gel. The plates were developed in chloroform/methanol/water/glacial acetic acid ( $65: 35: 4: 8$ by volume), by a modification of the techniques of Kulovitch et al. (10) and then dried. The phospholipids were visualized after charring, and measuring by reflectance densitometry.

\section{RESULTS}

Five rabbits in each group completed the entire protocol without developing any sign of air leaks. No differences were found in lung weights or flow rates between the two groups.

Resting pulmonary vascular resistance. Pulmonary vascular resistances were similar in both groups at the beginning of the perfusion and immediately after ductal ligation, both manifesting a sharp increase in pressure with ligation of the ductus (Fig. 1). However, after $2 \mathrm{~h}$ of perfusion, pulmonary pressures in the control groups had returned very nearly to preligation levels, while in the indomethacin-treated group, pulmonary pressures remained significantly elevated (Fig. 1; Table 1).

Circulation with First Inflation. The first full inflation pro-

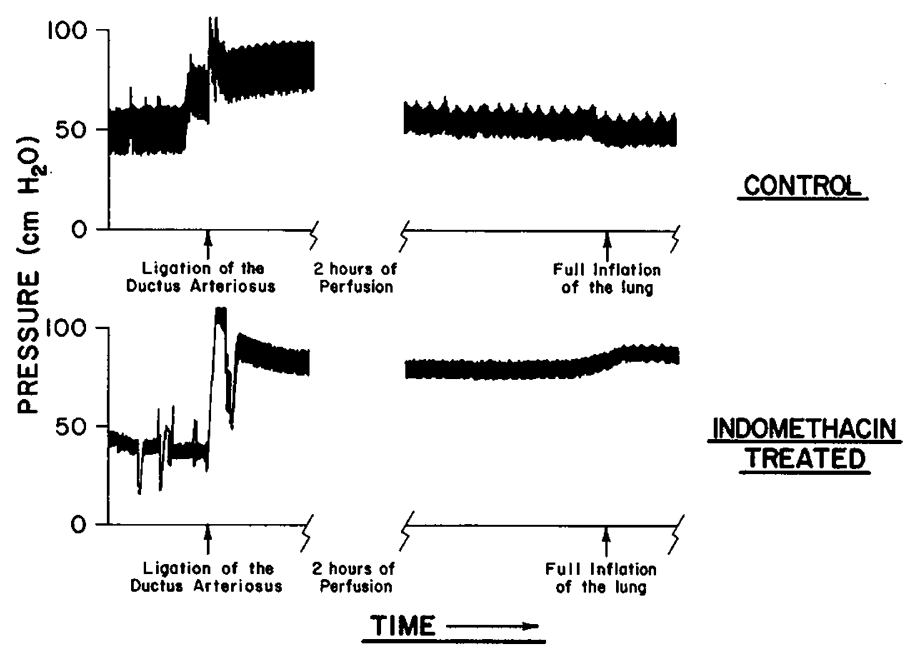

Fig. 1. Pulmonary artery pressure tracings. Note differences between rapid, acute rise in pulmonary artery pressure with ligation of the ductus and the more gradual changes with lung inflation. The upper panel demonstrates a perfused, untreated lung, showing the gradual decrease in pulmonary artery pressure with full expansion of the lung; the lower panel provides a sample of an indomethacin-treated lung demonstrating the increase in pulmonary artery pressure seen in these lungs.
Table 1. Values of pulmonary vascular resistance $(P V R$ in $\mathrm{cm}$ $\mathrm{H}_{2} \mathrm{O} / \mathrm{ml} / \mathrm{min}$ ) in both control and treated animals before and after ligation of the ductus*

\begin{tabular}{cccc}
\hline & & \multicolumn{2}{c}{ Postligation $\dagger$} \\
\cline { 3 - 4 } & Preligation & Immediate & After $2-\mathrm{hr}$ \\
\hline Control & $28.8 \pm 7.8$ & $44.2 \pm 10.1^{a}$ & $34.0 \pm 7.8^{b}$ \\
Treated & $32.0 \pm 7.3$ & $46.0 \pm 11.1$ & $42.0 \pm 10.2^{c}$ \\
\hline
\end{tabular}

* Means \pm SD are reported. PVR is significantly different, within the control group, between immediate and $2 \mathrm{~h}$ postligation, but not different in the treated group over the same time period. PVR is significantly different between the control and treated groups at $2 \mathrm{~h}$ postligation.

$\dagger p<0.10$ between $a$ and $b$ and between $b$ and $c$.

duced a slight fall in PVR in all control animals and a slight rise in PVR in all the treated rabbits $(p<0.05)$ (Table 2$)$.

Deflation to $P_{0}$ produced a fall in PVR to preinflation levels in the treated group. In control animals, deflation increased the PVR towards its preinflation levels.

Lung Inflation. Perfused but untreated lungs had higher volumes during inflation at $\mathrm{P}_{15}, \mathrm{P}_{20}$, and $\mathrm{P}_{25} \mathrm{~cm} \mathrm{H}_{2} \mathrm{O}$ and $\mathrm{P}_{\max }$ than indomethacin-perfused lungs, indicating greater airway stretch. They had significantly higher volumes at $\mathbf{P}_{\max }$, indicating greater saccular recruitment and distensibility. In addition, they had higher volumes of negative compliance and during deflation implying greater stability (Fig. 2). When pressures were dropped to $P_{0}$, treated lungs collapsed further and had volumes closer to $\mathrm{V}_{0}$ than did the controls who retained $15 \%$ of $\mathrm{V}_{\max }$ (Fig. 2).

Chemistries. Total phospholipid concentrations were not significantly different in lung tissue obtained from control perfused animals and from indomethacin-treated, perfused animals. L/S ratios, however, were higher in the control perfused lungs than the indomethacin-treated lungs $(p<0.05)$ (Table 3). These observations are consistent with the pressure/volume characteristics described. Since lavage fluid had to be pooled within a group, full statistical data are not available; however, both total phospholipids and $\mathrm{L} / \mathrm{S}$ ratios appeared to be greater in the control than the indomethacin-treated group (Table 3).

\section{DISCUSSION}

Functional adaptation to extrauterine life is dependent upon the successful interaction of several transitional events, most critically the onset of regular respiration and the provision of adequate pulmonary circulation, which, in turn, is related to the postnatal decrease in pulmonary vascular resistance. The specific contributions of various biochemical mediators to this process are not yet fully understood. Key roles have been postulated for oxygen, histamines, catecholamines, and other substances. Our interest here concerns the prostaglandins.

The effect of prostaglandins on pulmonary vasodilation has been studied by others under somewhat different circumstances. Kadowitz et al. (9) found that indomethacin infusion led to slow progressive increase in PVR of a breathing dog. They concluded that a dilator prostaglandin must be synthesized continuously to maintain a dilator tone in the pulmonary vascular bed. Leffler et al. (11) studied the newborn goat lung. They found no effect of indomethacin on nonventilated lung, but found an increase in PVR in ventilated animals treated with indomethacin. This effect was more pronounced in premature than full-term animals and in newborns than the several-days-old animals. They did not ligate the ductus arteriosus, however, and they attributed the increased PVR to increased pulmonary blood flow secondary to ductal constriction induced by the indomethacin.

In the present study, the effects of hemodynamic alterations secondary to ductal constriction were eliminated by ligating the ductus at the beginning of the perfusion. Therefore, the PVR data in the present study reflect the direct effect of prostaglandins on the pulmonary vascular bed.

From our data, it appears that the effect of prostaglandins on the pulmonary circulation is minimal in the unventilated fetal 
Table 2. PVR changes during inflation and deflation of the lungs*

\begin{tabular}{cccccc}
\hline & $\begin{array}{c}\text { Preinfla- } \\
\text { tion } \dagger\end{array}$ & $\begin{array}{c}\text { Postinfla- } \\
\text { tion } \ddagger\end{array}$ & $\begin{array}{c}\Delta \text { PVR } \\
\text { Pre } \rightarrow \text { Postinflation } \ddagger\end{array}$ & $\begin{array}{c}\Delta \text { Deflation } \ddagger \\
\text { (Infl } \rightarrow \text { Defl) } \dagger\end{array}$ \\
\hline Control & $34.0 \pm 7.8$ & $32.2 \pm 7.9$ & $-2.4 \pm 1.1$ & $31.8 \pm 6.6$ & $-0.4 \pm 1.9$ \\
Treated & $42.0 \pm 10.2$ & $44.6 \pm 12.1$ & $+2.6 \pm 2.4$ & $42.2 \pm 10.4$ & $-2.4 \pm 2.3$ \\
\hline
\end{tabular}

* There is a significant difference in PVR at inflation and deflation volumes between control and treated groups, and in $\Delta \mathrm{PVR}$ with inflation $(p$ $<0.05)$. Footnoted $p$ values in all cases measure difference between control and treated values. There is a significant difference in PVR at preinflation volume and in $\triangle$ PVR with deflation $(p<0.10)$.

$$
\begin{aligned}
& \dagger p<0.10 . \\
& \ddagger p<0.05 .
\end{aligned}
$$

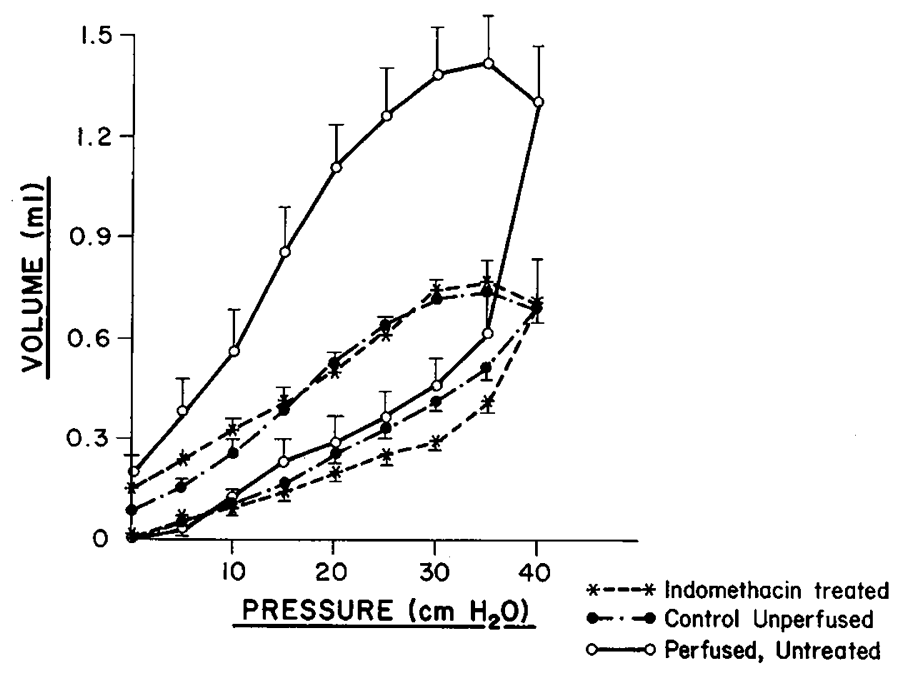

Fig. 2. Pressure volume diagrams. Note comparisons of age-matched control unperfused lungs $(\bullet)$, with perfused, untreated $(O)$, and with perfused, indomethacin-treated lungs $\left({ }^{*}\right)$.

Table 3. Values of lung phospholipids in control and treated groups

\begin{tabular}{lccccc}
\hline \multicolumn{2}{c}{ Control } & & \multicolumn{2}{c}{$\begin{array}{c}\text { Indomethacin } \\
\text { treated }\end{array}$} \\
\cline { 2 - 5 } \cline { 5 - 6 } & $\begin{array}{c}\text { Lung tissue } \\
(\mathrm{mg} / \mathrm{g})\end{array}$ & $\begin{array}{c}\text { Lung lavage } \\
(\mu \mathrm{g} / \mathrm{ml})\end{array}$ & $\begin{array}{c}\text { Lung tissue } \\
(\mathrm{mg} / \mathrm{g})\end{array}$ & $\begin{array}{c}\text { Lung lavage } \\
(\mu \mathrm{g} / \mathrm{ml})\end{array}$ \\
\hline Total phospholipid & $0.13 \pm 0.04$ & 7.36 & $0.11 \pm 0.02$ & 2.54 \\
L/S ratio & $1.33 \pm 0.13^{*}$ & 2.08 & & $0.93 \pm 0.06^{*}$ & 0.77 \\
\hline
\end{tabular}
0.05 .

lung. Ductal ligation produces a rapid hemodynamic, mechanical increase in PVR. The pulmonary circulation accommodates to this by gradual lowering of PVR. This adaptation is blocked by indomethacin, and thus seems to be mediated by release of some prostaglandin-related substance (Fig. 1).

The drop in PVR with the first inflation as observed in our control lungs is consistent with that observed clinically in vivo with the onset of respiration. Again, this effect appears to be eliminated by indomethacin therapy which implies that it too is at least partially mediated by prostaglandins (Fig. 1).

Thus, in this model, prostaglandins appear to have a significant role at two key points in transition: 1) the gradual accommodation to mechanically or hemodynamically mediated increases in PVR, and 2) the drop in pulmonary vascular resistance which occurs with the first inflation of the lungs.

Some aspects remain unexplained, most notably the increase in PVR with inflation in the treated group. It is possible that, by blocking the prostaglandin system, the effects of some other mediators providing a balancing constrictor tone have been uncovered; however, this is only speculation at this point.

Also, it must be noted that this is only an experimental model in an unphysiologic setting and may not accurately reflect the normal physiologic situation. Further documentation in vivo is necessary to confirm the above conclusions.

Possible interactions between the prostaglandins and the surfactant system are even less clear. Anderson et al. (1) studied the effects of prostaglandin $F_{2 r}$ on adult rat type II alveolar epithelial cells in culture which were already treated with dexamethasone. They found that, although dexamethasone increased intracellular lecithin formation, it did not appear to affect release. However, prostaglandin $F_{2 x}$ caused release of the lecithin from cells.

Oyarzun and Clements (12) studied indomethacin effects on adult rabbits under conditions of normal ventilation or hyperventilation, which increases release of surfactant. They found no change from controls when prostaglandin inhibitors were administered during normal ventilation, indicating that the role of prostaglandins under basal conditions is minimal. When they administered indomethacin to hyperventilated animals, however, they found the expected increase in phospholipids to be blocked, possibly implicating a role for prostaglandins in phospholipid synthesis or release under some specific circumstances.

Our volume-pressure diagrams show higher volumes in the untreated perfused lungs than those seen in untreated, unperfused rabbit lungs of the same gestational age (13). This implies greater airway stretch, saccular recruitment, and stability. Increased surfactant mobilization via the perfusion itself can account for this. In fact, Bondurant and Miller (3) have described perfusion of the pulmonary vasculature as a technique for increasing the yield of surface active material from lung extracts.

Our indomethacin-treated volume/pressure diagrams, however, are similar to those of untreated, unperfused lungs (13). Thus, indomethacin, either through vasoconstriction or through blockage of surfactant release, appears to inhibit the increased mobilization of surfactant seen in the untreated, perfused lungs. There is no evidence for any direct effect of prostaglandins on surfactant synthesis. These conclusions are consistent with the biochemical data.

In summary, the effects of indomethacin treatment on pulmonary vascular resistance with the first lung inflation, on inflation characteristics, and on total phospholipids and $L / S$ ratios have been studied in fetal rabbit lungs. Inhibition of prostaglandin synthesis was found to also inhibit 1) the gradual accommodation response to PVR to hemodynamic alterations produced by ductal ligation observed in control preparations, and 2) the drop in PVR normally observed within the first inflation of the lungs.

This implies that prostaglandins play an active role in these two aspects of transition. No direct effect of prostaglandin inhibition on surfactant production was documented. Again, it must be emphasized that this is only an isolated heart-lung preparation and any broader systemic applications would first require further study.

Acknowledgment. We would like to thank Dr. Morton Rosenberg of Merck, Sharpe \& Dohme Research Laboratories for his gracious donation of indomethacin.

\section{REFERENCES}

1. Anderson G, Cidlowski J, Abshu P, Hewitt J, Douglas W 1978 The effect of dexamethasone and prostaglandin $F_{2 \alpha}$ on production and release of surfactant in type II alveolar cells. Prostaglandins 16:923 
2. Beveridge J, Johnson S 1949 Determination of phospholipid phosphorus. Can J Res Sect E27:159

3. Bondurant S, Miller D 1962 A method for producing surface active extracts of mammalian lungs. J Appl Physiol 17:167

4. Cassin S 1980 Role of prostaglandins and thromboxanes in the control of the pulmonary circulation in the fetus and newborn. Sem Perinatol 4:101

5. Challis J, Dilley S, Robinson J, Thorburn G 1976 Prostaglandins in the circulation of the fetal lamb. Prostaglandins 11:1041

6. Challis J, Osathanondh R, Ryan K, Tulchinsky D 1974 Maternal and fetal plasma prostaglandin levels at vaginal delivery and caesarian section. Prostaglandins $6: 281$

7. Colacicco G. Basu M, Ray A, Wittner M, Roenbaum R 1977 Effects of prostaglandins $E_{2}$ and $F_{2 \varkappa}$ on lecithin biosynthesis by cultured lung cells. Prostaglandins 14:283
8. Folch J, Lees M, Sloan-Stanley G 1957 A simple method for the isolation and purification of total lipids from animal tissues. J Biol Chem 226:497

9. Kadowitz P, Chapnick B, Joiner P. Hyman A 1975 Influence of inhibitors of prostaglandin synthesis on the canine pulmonary vascular bed. Am J Physiol 229:941

10. Kulovich M, Hallman M, Gluck L 1979 The lung profile. Am J Obstet Gynecol 135:57

11. Leffler C. Tyler T, Cassin S 1978 Effect of indomethacin on pulmonary vascular response to ventilation of fetal goats. Am J Physiol 234:H346

12. Oyarzun M, Clements M 1978 Vetilation, prostaglandins and autonomic mediators in regulation of pulmonary alveolar surfactant content in rabbits. Am Rev Respir Dis 117:879

13. Scarpelli EM, Kumar A, Doyle C, Clutario B 1981 Functional anatomy and volume-pressure characteristics of immature lungs. Respir Physiol 45:25

\title{
Growth-related Changes in Oxygen Uptake and Heart Rate during Progressive Exercise in Children
}

\author{
DAN M. COOPER*, DANIEL WEILER-RAVELL, BRIAN J. WHIPP, AND \\ KARLMAN WASSERMAN \\ Division of Respiratory Phsyiology and Medicine, Department of Medicine, and Department of Pediatrics, \\ University of California, Los Angeles, School of Medicine, Harbor-UCLA Medical Center. \\ Torrance, California 90509
}

\section{Summary}

Although body size and muscle mass increase considerably during growth in children, certain aerobic responses to exercise appear to be regulated so that the delivery of oxygen to muscle is maintained at optimized levels. We proposed that the relationship between oxygen uptake, $\left(\dot{\mathrm{V}}_{2}\right)$ and heart rate $(\mathrm{HR})$ was one of the regulated responses. We further hypothesized that the increase in $\mathrm{VO}_{2}$ per increase in $\mathrm{HR}$ during progressive exercise would differ in subjects of different size, but when normalized to body weight would be constant since changes in muscle mass are highly correlated to changes in body mass. To test this, we performed a cross-sectional study of 107 normal children, 50 girls and 57 boys ranging in age from 6 to 17 years. The protocol consisted of a continuously increasing work rate on a cycle ergometer, to the limit of the child's tolerance (ramp forcing function). Gas exchange was measured breath-by-breath for the determination of $\dot{\mathrm{VO}}_{2}$, and heart rate was measured beat-by-beat. We used linear regression techniques to determine $M$, the slope, and $B$, the $y$ intercept of the equation: $\dot{V O}_{2}=M \times H R-B$. In both boys and girls, $M$ increased significantly with body weight, but when normalized for body weight $(M / \mathrm{kg})$, there was no systematic change with increasing weight or age, the mean value being $0.33 \pm 0.10 \mathrm{ml} / \mathrm{min} / \mathrm{kg}$ (SD). The mean value for the boys was $0.37 \pm 0.10$ which was significantly greater than that of the girls $(0.29 \pm 0.08, p<0.01)$. Using allometric equations, we found $M, B$, and the $\mathrm{O}_{2}$-pulse $\left(\dot{V}_{2} / \mathrm{HR}\right)$ at a heart rate of 140 beats/min and at the anaerobic threshold, all scaled in direct

Received July 8, 1983; accepted February 7, 1984.

Reprint requests may be addressed to Dan M. Cooper, M.D. A-15 Annex, Harbor-UCLA Medical Center. Torrance, CA 90509.

- Senior Investigator of the American Heart Association, Greater Los Angeles Affiliate. proportion to body weight (i.e., to 1.0 power of body weight). We conclude that during growth, the output of the heart is closely tied to the size of the muscles so that delivery of oxygen during exercise is maintained at optimized levels from early in childhood.

\section{Abbreviations}

$\dot{V}_{\mathrm{O}_{2}}$, oxygen uptake

$\grave{V O}_{2}$ max, maximum oxygen uptake

$A T$, anaerobic threshold

HR, heart rate

SV, stroke volume

$(a-\bar{v}) \mathrm{O}_{2}$, arteriovenous oxygen content difference

We have recently demonstrated that certain aerobic parameters of exercise appear to be highly regulated as body weight changes during growth in children. The work efficiency and the response time for $\dot{\mathrm{V}}_{2}$ following the onset of exercise are independent of body size, whereas the $\mathrm{V}_{2}$ max and the $A T$ increase in direct proportion to body weight (6). Moreover, the $\dot{\mathrm{VO}}_{2}$ increases linearly with work rate in both adults and children $(6$, 19 ) indicating that as more muscle units are activated, the flow of oxygen is optimized so that a unique work efficiency is maintained at virtually all levels of energy demand. In addition, other investigators have shown that the relationship between $\mathrm{VO}_{2}$ and $\mathrm{HR}$ is linear during progressive exercise in children, and that the $\mathrm{VO}_{2}-\mathrm{HR}$ relationship changes in a systematic way as children grow $(1,9)$.

Based on these observations and on the concept that the cellular milieu must be maintained within a narrow range of temperature and $\mathrm{pH}$, we proposed that the $\dot{\mathrm{V}}_{2}$ - $\mathrm{HR}$ relationship 